\title{
Dynamic Response of Composite Steel Lining Structure under Blast Loading
}

\author{
Desen Kong ${ }^{(D,}{ }^{1,2}{ }^{1}$ X Xu, ${ }^{1}$ and Cheng Song ${ }^{3}$ \\ ${ }^{1}$ School of Civil Engineering and Architecture, Shandong University of Science and Technology, Qingdao 266590, China \\ ${ }^{2}$ Shandong Key Laboratory of Civil Engineering Disaster Prevention and Mitigation, Qingdao 266590, China \\ ${ }^{3}$ No. 4 Engineering Company Ltd. of China Communications Construction, First Harbor Engineering Company Ltd., \\ Tianjin 300000, China \\ Correspondence should be addressed to Desen Kong; skd992012@sdust.edu.cn
}

Received 21 November 2019; Revised 17 March 2020; Accepted 25 May 2020; Published 30 June 2020

Academic Editor: Athanasios Chasalevris

Copyright (C) 2020 Desen Kong et al. This is an open access article distributed under the Creative Commons Attribution License, which permits unrestricted use, distribution, and reproduction in any medium, provided the original work is properly cited.

\begin{abstract}
According to the advantages of high tensile resistance and high shear strength of composite steel plate, a new antiexplosion protection method of composite steel plate lining structure is put forward. The numerical model of explosion impact of subway tunnel with composite steel plate lining structure was established by dynamic analysis software. The transient dynamic response of lining structure with the composite steel plate was simulated when explosion occurred. The research results show that the influence of explosive quantity on each point of composite steel plate lining structure is different and the change of acceleration near the centre of the detonation source is generally greater than the multiple of the increase of explosive quantity. The increase of velocity and displacement is basically consistent with the quantity of explosive. The influence of axial stress on the lining structure is the least, and the influence of the lining structure is greater in the $y$-direction than in the $x$-direction. The research results can provide the plan and basis for the emergency response of the subway tunnel.
\end{abstract}

\section{Introduction}

With the acceleration of the modernization process, the construction of subway is not only the best solution to the traffic jam problem but also the catalyst to promote the modernization process. As an effective tool to solve the inconvenience of citizens, subway tunnels sometimes become places where terrorists carry out terrorist bombings. In order to protect the safety of real citizens and reduce the loss of public property, subway tunnel structures should have sufficient antiexplosion capability. Therefore, it is of great theoretical value to study the role of composite steel plates in subway tunnel protection [1-3].

In the field of subway tunnel protection, scholars at home and abroad have carried out a large number of experiments and numerical simulation studies. Liu et al. [4] used LS-DYNA software to carry out explosion numerical simulation on equivalent explosive amounts of $10 \mathrm{~kg}, 20 \mathrm{~kg}$, and $30 \mathrm{~kg}$ TNT and obtained the results that the structure cannot be damaged at $10 \mathrm{~kg}$, the structure can be damaged at $20 \mathrm{~kg}$, and the structure can be completely damaged at $30 \mathrm{~kg}$. Zyskowski et al. [5] studied the dynamic response of the internal explosion load of the structure by using a reduced scale model for internal explosion simulation and a numerical simulation method. Yan and Cao $[6,7]$ obtained the pressure variation curves when the explosion occurred in the tunnel structure by constructing different structural models of underground tunnels and tunnels and conducting a numerical simulation of explosion and experimental research in different proportions. However, there are still a lot of gaps in the research on the protection of composite materials in subway tunnels, especially its protection characteristics and dynamic response analysis which still need to be vigorously studied.

A new type of explosion-proof structure of composite steel plate lining structure was proposed. Based on the knowledge of explosion mechanics and fluid dynamics, a numerical model of explosive-air-composite steel plate- 
lining-surrounding soil was established by dynamic analysis software LS-DYNA. The instantaneous dynamic response of lining structure with composite steel plate when explosion occurs was simulated, and the stress characteristics of lining structure under different explosive equivalent are obtained.

\section{Establishment of Numerical Model of Composite Steel Plate Lining Protection Structure}

2.1. Composite Steel Plate Lining Protection Structure. The traditional composite steel plate is mostly used to prevent vibration and noise. According to this characteristic, the composite steel plate is extended to the tunnel protection. The two remarkable characteristics of the composite steel plate are the difference of interface bond ratio and interface shear strength, as well as the tensile, bending, hardness, and other properties required by protective materials. The preparation methods of composite steel plate can be divided into rolling method, surfacing method, explosive welding method, and explosive welding rolling method. The rolling method is to seal the joint between the cladding and the base and to weld and vacuum-roll. The manufacturing process is simple, but the disadvantages are obvious. The steel plate specification is small, and the quality of the interface joint is poor. The cost of using the surfacing method to make largearea steel plate is too high. The explosive welding rolling method is similar to the explosive welding method. However, the explosive welding rolling method is used in China. The composite steel plate cannot be widely used due to poor coordination. The composite steel plate is composed of two layers of steel plate and high-strength polyester fiber. The high-strength polyester fiber is between two layers of steel plate, and its thickness ratio is $2: 1: 2$, which is made by the explosive welding method. The two basic characteristics of composite steel plate, interface binding rate and interface shear strength, have reached the relevant standards. The composite steel plate structure is as shown in Figure 1.

According to the nonlinear characteristics of shock reflection during the propagation of explosion shock wave in explosion activities, the protection steel plate adopts the model of ordinary steel plate and takes into account the characteristics of laminated composite steel plate. The material model of protection steel plate adopts the bilinear elastoplastic constitutive model [8]. The strain rate effect of composite steel plate material is expressed by Cowper-Symonds model [9], and its dynamic yield strength $\sigma_{y}$ can be expressed as follows:

$$
\sigma_{y}=\left[1+\left(\frac{\varepsilon}{D}\right)^{1 / p}\right]\left(\sigma_{0}+\beta E_{p} \varepsilon_{p}^{\text {eff }}\right),
$$

where $\sigma_{0}$ is the initial yield strength; $\varepsilon$ is the strain rate; $E_{p}$ is the plastic hardening modulus; $\varepsilon_{p}^{\text {eff }}$ is equivalent plastic strain. $\beta$ is the hardening parameter. When the parameter is 0 , it means follow-up hardening occurs, and when the parameter is 1 , it means isotropic hardening occurs. $D$ and $P$ are strain rate parameters.

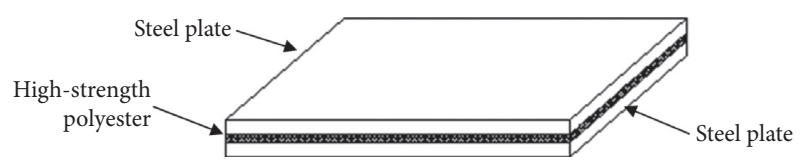

Figure 1: Composite steel plate structure.

2.2. Establishment of Composite Steel Plate Lining Protection Structure Model. According to the engineering background of Nanjing subway tunnel, the explosive-air-composite steel plate-lining-surrounding soil model is established by using finite element software LS-DYNA [10]. Figure 2 is the structural diagram of composite steel plate lining structure model. In the numerical simulation, it is mainly divided into five parts: explosive unit, air unit, composite steel plate unit, lining structure unit, and soil unit. Each part of the unit is divided by mapping grid, with the grid side length of $100 \mathrm{~mm}$ and the grid side length of $300 \mathrm{~mm}$ in the distance of the soil unit. Since the whole model is an axisymmetric model, it takes $1 / 2$ of the model to save the calculation time. The whole model has 961767 elements.

The model is a cylindrical shield tunnel with a soil depth of $15 \mathrm{~m}$. The shield tunnel has a lining thickness of $0.3 \mathrm{~m}$, inner diameter of $5.4 \mathrm{~m}$, outer diameter of $6.0 \mathrm{~m}$, and protective steel plate thickness of $0.1 \mathrm{~m}$. The numerical simulation of the model can be regarded as an axisymmetric problem, so a $1 / 2$ model is adopted for modeling and calculation, and a $36 \times 36 \times 15$ cube is taken to form a whole model to reduce the influence of boundary effect. The equivalent TNT algorithm is used to simulate the point source explosion at a distance of $1.1 \mathrm{~m}$ from the bottom of the tunnel lining structure under the equivalent of $10 \mathrm{~kg}$ TNT and $30 \mathrm{~kg}$ TNT.

\subsection{Explosive Combustion Model and Parameters.} Because of the short reaction time and the fast propagation speed of the blast wave, the time of the blast wave propagating to the interface between the charge and the medium is very short, which can be ignored generally, so only the external reaction of the explosion is studied.

The equivalent TNT conversion is carried out by LSDYNA program, and the keyword “* MAT-HIGHEXPLOSIVE-BURN" is used to simulate the detonation of high-energy explosives [11]. The relevant parameters of explosives are listed in Table 1.

In the numerical simulation of explosion, the explosion source explosive is simulated by JWL equation of state [12], and the pressure is expressed by the function of initial volume and relative volume:

$$
P=A\left(1-\frac{\omega}{R_{1} V}\right) e^{-R_{1} V}+B\left(1-\frac{\omega}{R_{2} V}\right) e^{-R_{2} V}+\frac{\omega E_{0}}{V},
$$

where $P$ is pressure; $A, B, R_{1}, R_{2}$, and $\omega$ are the material function coefficients, respectively; $V$ is the relative volume; $E_{0}$ is the initial internal energy per unit volume. The state equation uses the "*EOS-JWL" keyword provided by LSDYNA program, and the parameters are listed in Table 2. 


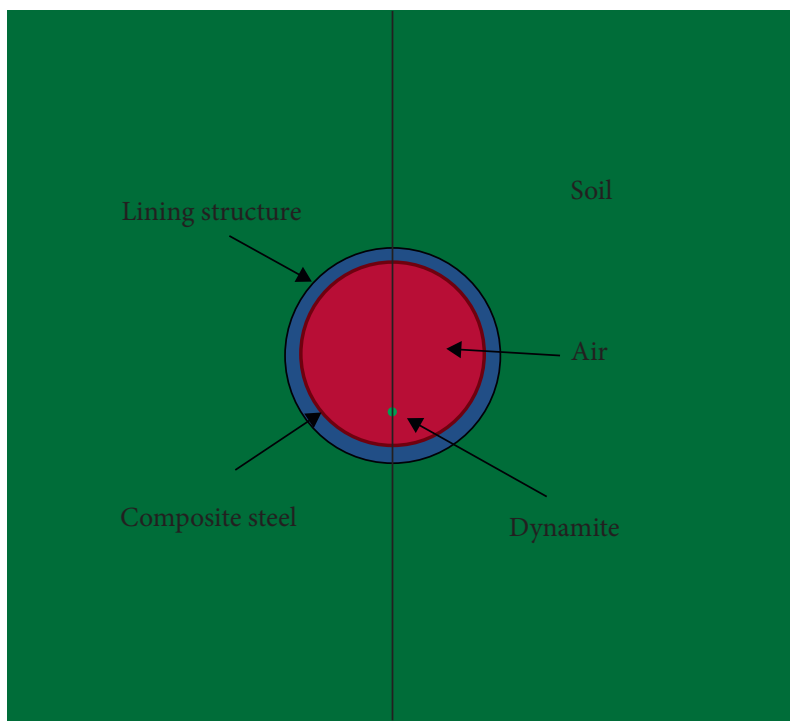

FIGURE 2: Composite steel lining structure mode.

Table 1: Parameters of explosive material.

\begin{tabular}{lcccc}
\hline Density $\left(\mathrm{g} / \mathrm{cm}^{3}\right)$ & Burst velocity $(\mathrm{mm} / \mu \mathrm{s})$ & Pressure $C J$ & Bulk modulus $(\mathrm{Pa})$ & Shear modulus $(\mathrm{Pa})$ \\
\hline 1.63 & 0.693 & 0.27 & 0 & 0 \\
\hline
\end{tabular}

Table 2: Parameters of JWL equation of state.

\begin{tabular}{ccccccc}
\hline$A$ & $B$ & $R_{1}$ & $R_{2}$ & $\omega$ & $E_{0}$ & $V_{0}$ \\
\hline 3.74 & $3.23 \times 10^{-2}$ & 4.15 & 0.95 & 0.3 & $0.07 \times 10^{11}$ & 1.0 \\
\hline
\end{tabular}

2.4. Model Parameters of Surrounding Soil. In numerical simulation, the soil structure is chosen to be a flattened plastic foam model and a soil with failure characteristics, that is, the MAT- SOIL-AND-FOAM model [13]. The yield function $f$ of the model adopts the following formula:

$$
f=J_{2}-\left(a_{0}+a_{1} p+a_{2} p^{2}\right) .
$$

The soil in the numerical simulation is set by Drucker-Prager yield criterion, which can be obtained by the angle of internal friction $\varphi$ and cohesion $c$ of soil:

$$
\begin{gathered}
\alpha=\frac{\sin \varphi}{\sqrt{9+3 \sin ^{2} \varphi}}, \\
k=\frac{\sqrt{3} c \cos \varphi}{\sqrt{3+\sin ^{2} \varphi}} .
\end{gathered}
$$

2.5. Lining Structure Model and Parameters. In the numerical simulation, the lining structure adopts the $\mathrm{h}-\mathrm{j}-\mathrm{c}$ model, which was initially used to simulate brittle materials, such as glass and ceramics, before it was developed to simulate concrete. The model can be well utilized to solve the concrete and rock simulation problems in the case of high strain rate and large deformation complex. Therefore, this model is adopted. The h-j-c model in LS-DYNA 3D is defined as ${ }^{*}$ MAT-JOHENS-HOLMUST-CONCRETE. The material number is 115 .

2.6. Air Model and Parameters. In the numerical simulation, the material model of air is assumed to be an ideal gas, and the relationship between pressure $P$ and energy $E$ can be expressed as follows:

$$
P=(\gamma-1) E,
$$

where $\gamma$ is the specific heat ratio of gas, which takes the value of 1.4 , the relative density $\rho_{0}$ of air takes the value of $1.29^{*} 10^{-3} \mathrm{~kg} / \mathrm{m}^{3}$, and the initial internal energy $E$ of unit volume takes the value of $0.25 \mathrm{MPa}$.

\section{Analysis of Numerical Calculation Results}

3.1. Stress Changes of Explosion Shock Wave on Tunnel Structure. For the shock wave generated by the explosion in the subway tunnel, its propagation law is very complex [14]. In order to better study this kind of complex situation, LSDTYNA dynamics software is used, under the equivalent of $10 \mathrm{~kg}$ TNT and $30 \mathrm{~kg}$ TNT, respectively, $1.1 \mathrm{~m}$ from the bottom of the lining. When the explosion occurs, under the protection of composite steel plate, the dynamic response of the subway tunnel only observes the air part of the model. For mechanical properties, Figures 3 and 4 are shock-wave stress nephogram of lining structure under the action of $10 \mathrm{~kg}$ TNT and $30 \mathrm{~kg}$ TNT, respectively. 

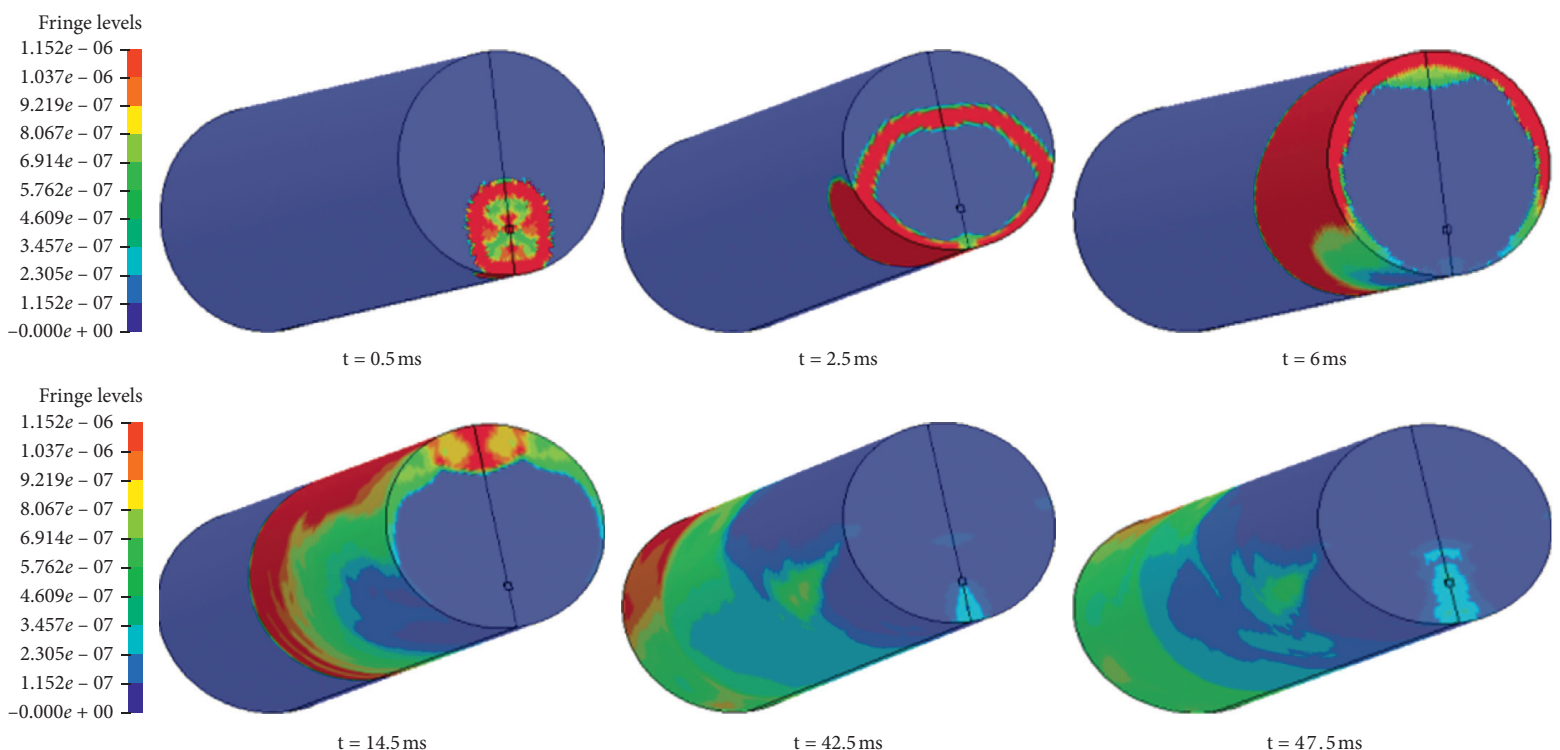

Figure 3: The process of blast wave under $10 \mathrm{~kg}$ TNT at different time period.

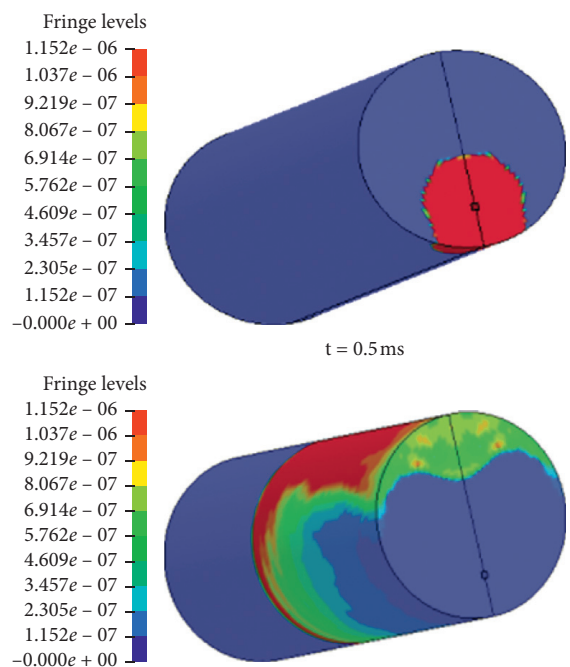

$\mathrm{t}=14.5 \mathrm{~ms}$
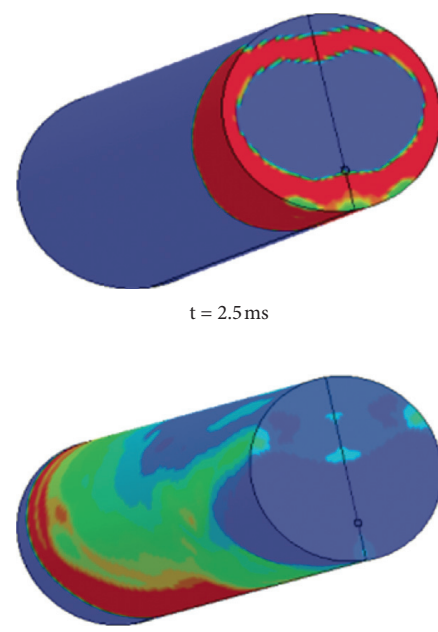

$\mathrm{t}=42.5 \mathrm{~ms}$

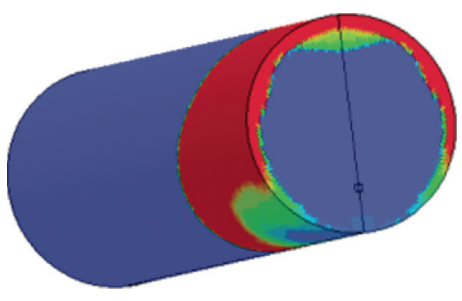

$\mathrm{t}=6 \mathrm{~ms}$

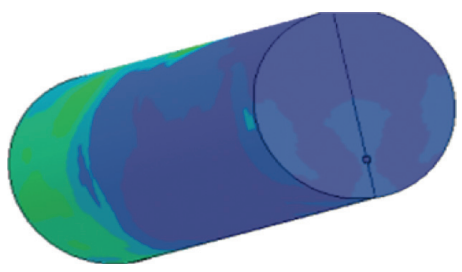

$\mathrm{t}=47.5 \mathrm{~ms}$

FIgURE 4: The process of blast wave under $30 \mathrm{~kg}$ TNT at different time period.

Considering the short action time and high frequency of explosion shock, it only takes a few milliseconds from the zero load to the maximum load, and the stress-strain behavior of the structure under the action of shock wave is positively correlated with the action rate of shock wave. Therefore, in order to better study the destructive effect of the peak value of explosion load, the numerical model has an explosion time of $50 \mathrm{~ms}$ [15].

The explosive propagates to all sides after the explosion. Under the influence of no obstacles, the blast wave will form a spherical wave array and propagate outwards. Because the explosion point is $1.1 \mathrm{~m}$ away from the bottom lining, the distance is relatively short, so the first contact with the bottom of the lining will increase the pressure, generate the reflected wave, and propagate to the distance. With the increase of the distance, the pressure of the blast wave will continue to decrease because of the superposition of the shock wave. The reflection wave at the bottom overlaps with the weakened shock wave, which makes the propagation speed faster. In about $5 \mathrm{~ms}$, the shock wave propagates to the top lining, and then it reflects downward and spreads to the distance. Because the reflection wave overlaps many times in the subway section tunnel, the reflection wave experiences many peaks in each point inside the tunnel and slows down its weakening effect. Because the shock wave starts to spread as a spherical wave, it spreads in the lining. The shock wave at the top is composed of two parts, the wave front of the spherical wave and the reflection wave of the lining at the top. The reflection wave will continue to reflect downward in the process of propagation. In this process, some reflection waves will 


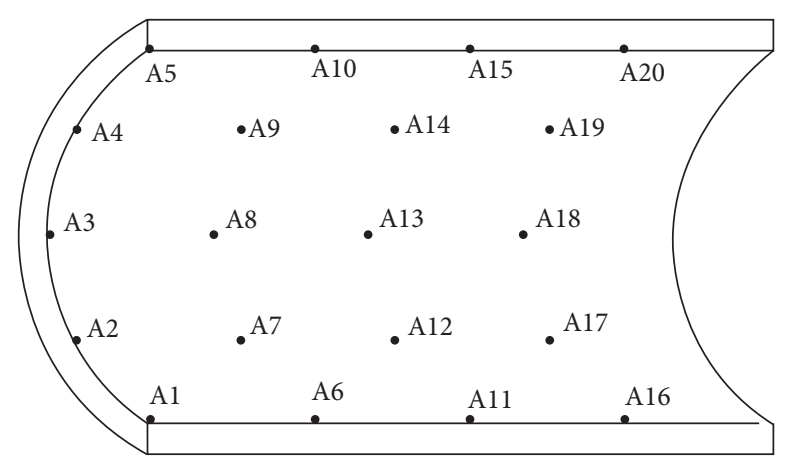

FIGURE 5: Observation points of tunnel liner.

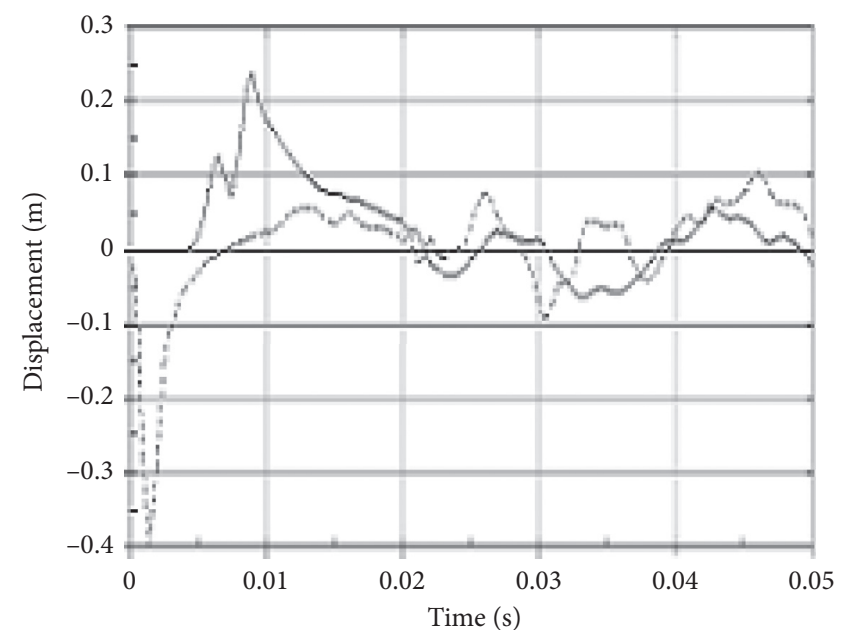

…. A1

_ A5

(a)

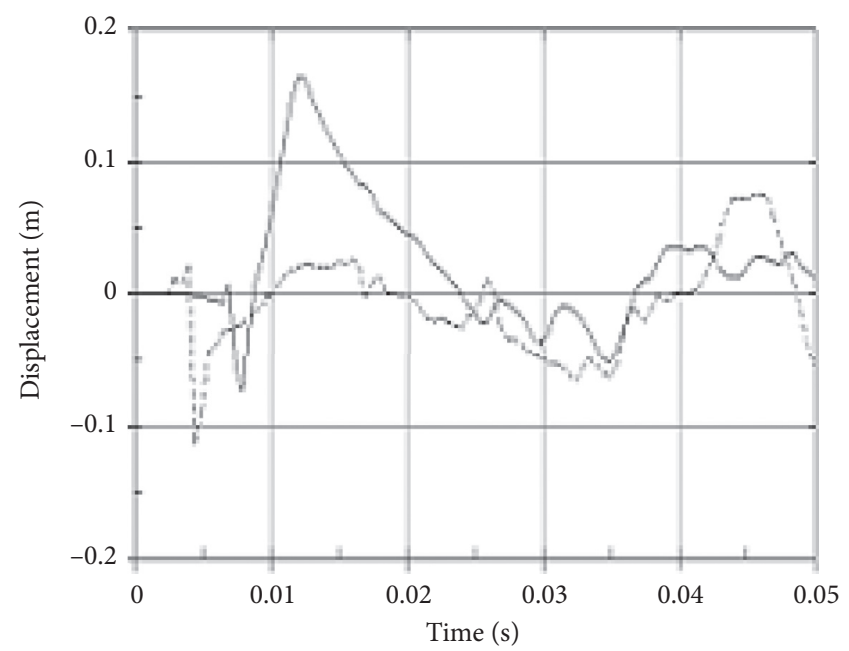

..... A11

- A15

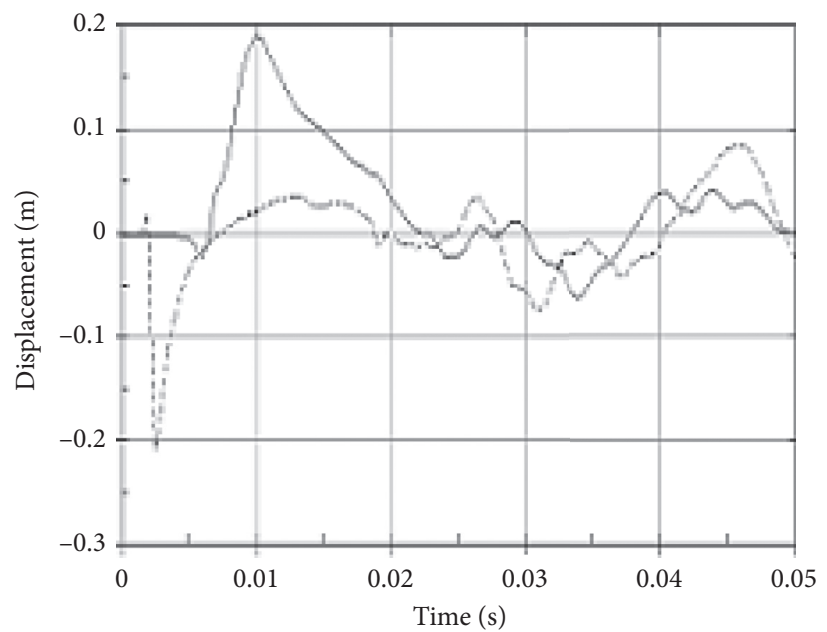

…. A6

- A10

(b)

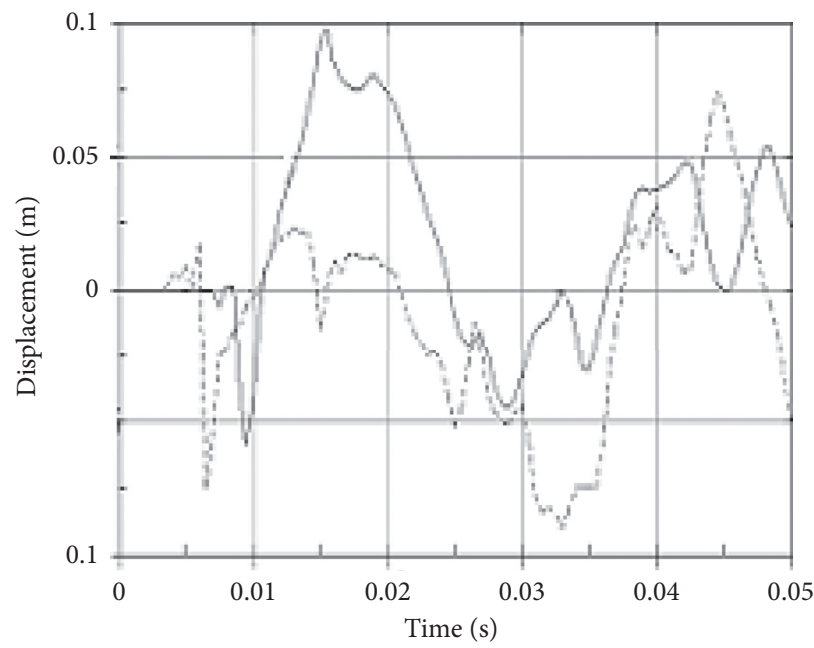

..... A 16

- A20

(c)

(d)

Figure 6: Changes of displacement in $y$-direction in sections. (a) Reference point of section one, (b) reference point of section two, (c) reference point of section three, and (d) reference point of section four. 


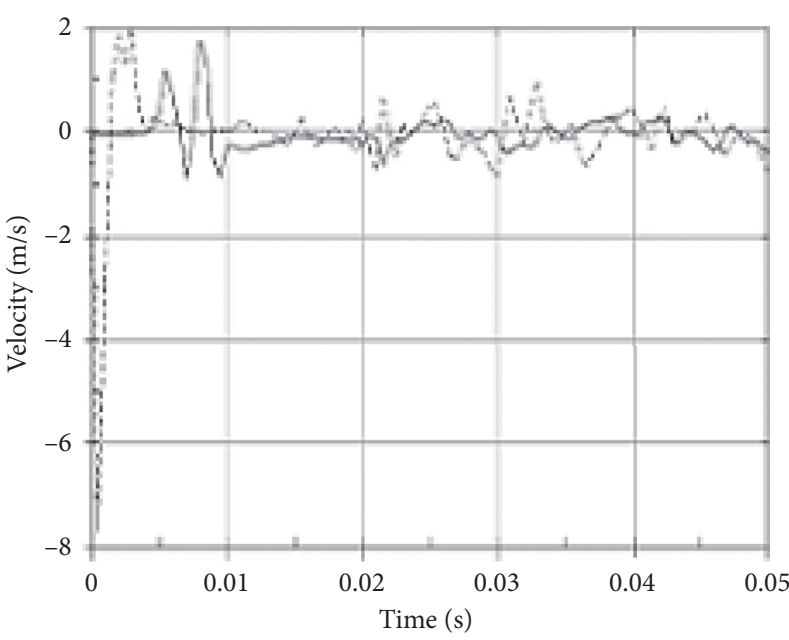

..... A1

- A5

(a)

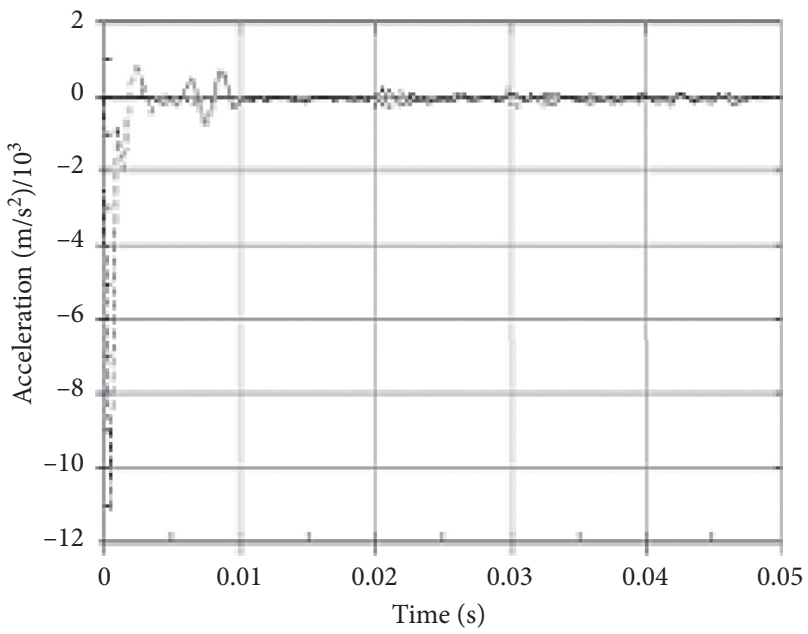

A11

- A15

(c)

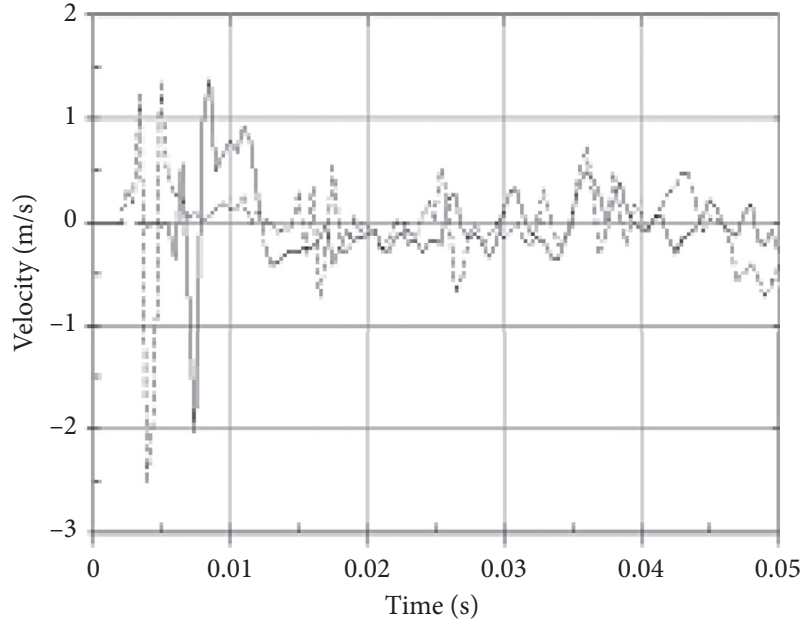

… A1

- A5

(b)

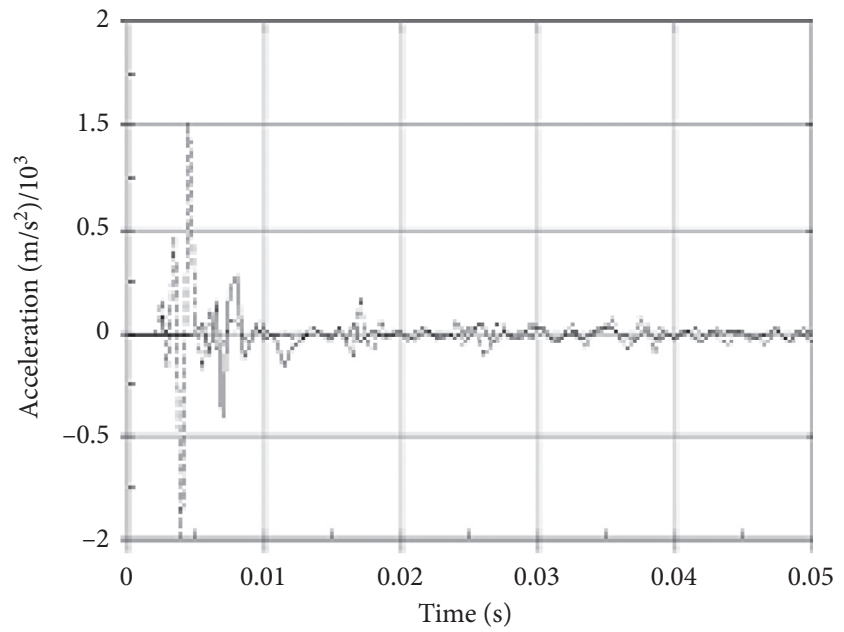

A11

- A15

FIGURE 7: Velocity and acceleration curves in $y$-direction on each section. (a) Velocity in $y$-direction of section one, (b) velocity in $y$ direction of section three, (c) acceleration of section one in $y$-direction, and (d) acceleration of section three in $y$-direction.

propagate in the opposite direction, resulting in multiple stress peaks on the explosion source section: $30 \mathrm{~kg}$ TNT. Compared with $10 \mathrm{~kg}$ TNT, the blast energy is more powerful, and the impact range of shock wave is wider. For the explosion activities in the closed structure, the peak value of shock wave is strengthened due to the multiple reflection and superposition of blast wave, each point experiences multiple peaks, its duration is increased, and its shock propagation law is more complex. In the early stage of explosion activities, the bottom blast wave propagation is faster, and in the process of propagation, when the upper shock wave undergoes reflection and superposition, the propagation speed will be accelerated, which also accords with the characteristics that the blast wave is a spherical wave [16].
3.2. Dynamic Response of the Lining Structure under the Blast Action. When an explosion occurs in the tunnel section, the displacement, velocity, and acceleration of the lining structure under the action of the explosion are important parameters to measure the damage degree of the structure [16]. In order to study the dynamic response of the lining structure under the action of explosives equivalent to $10 \mathrm{~kg}$ and $30 \mathrm{~kg}$ under the protection of composite steel plate, 20 reference points were selected where the influence of the lining structure was obvious and divided into four groups. These four groups were arranged on sections at different distances from the explosion source centre, numbered $\mathrm{A} 1-\mathrm{A} 20$, and were $0 \mathrm{~m}, 3 \mathrm{~m}, 6 \mathrm{~m}$, and $9 \mathrm{~m}$ away from the explosion centre. Figure 5 is the layout diagram of each reference point of the lining structure [17-19]. 

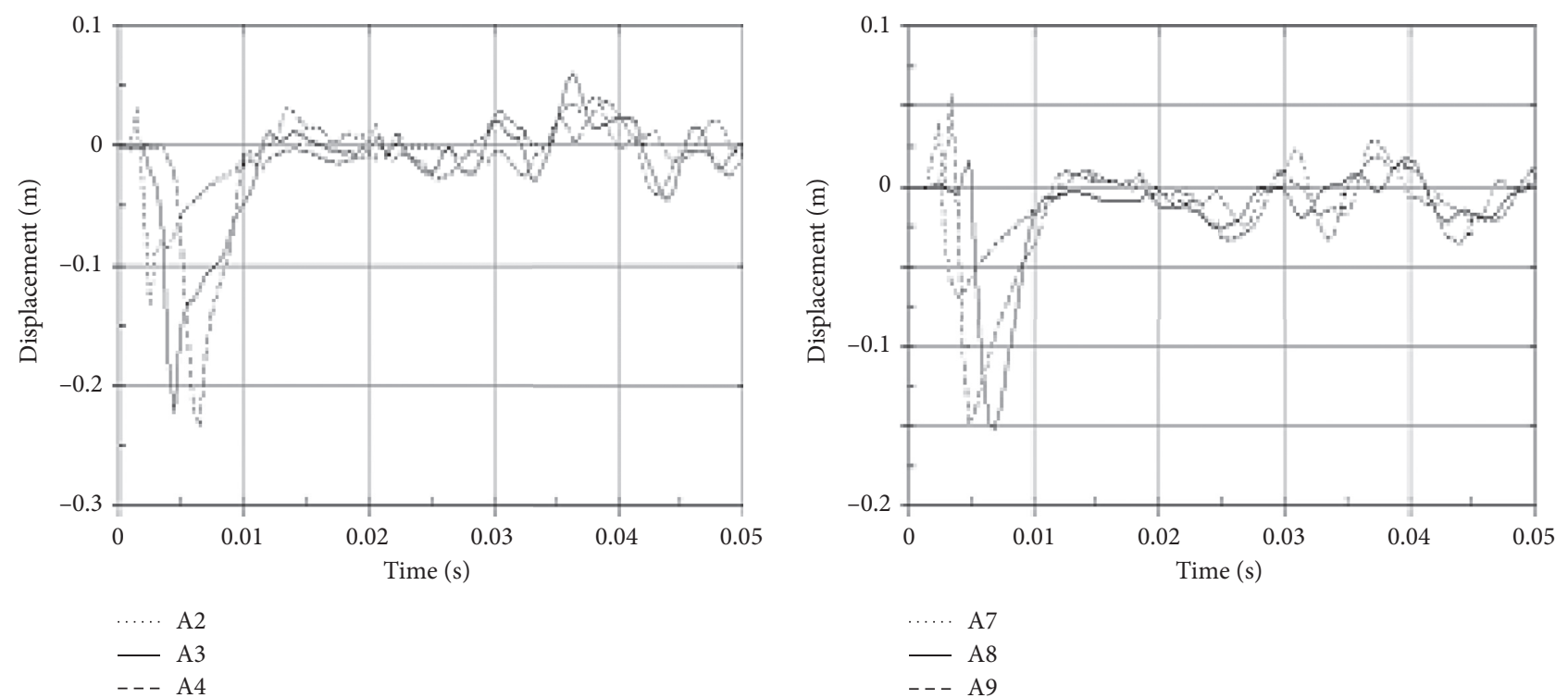

(a)

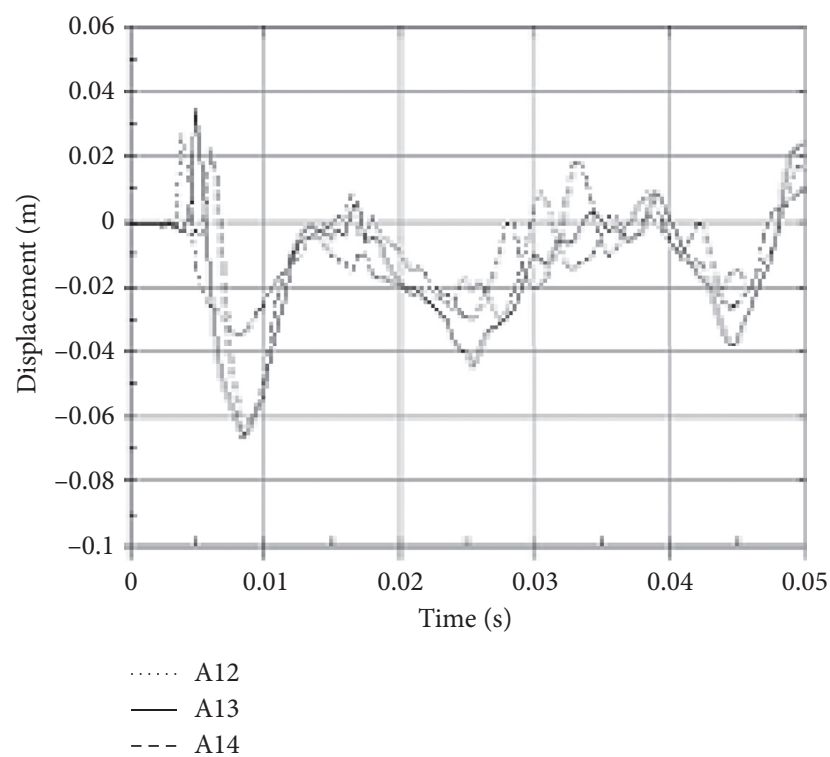

(c)

(b)

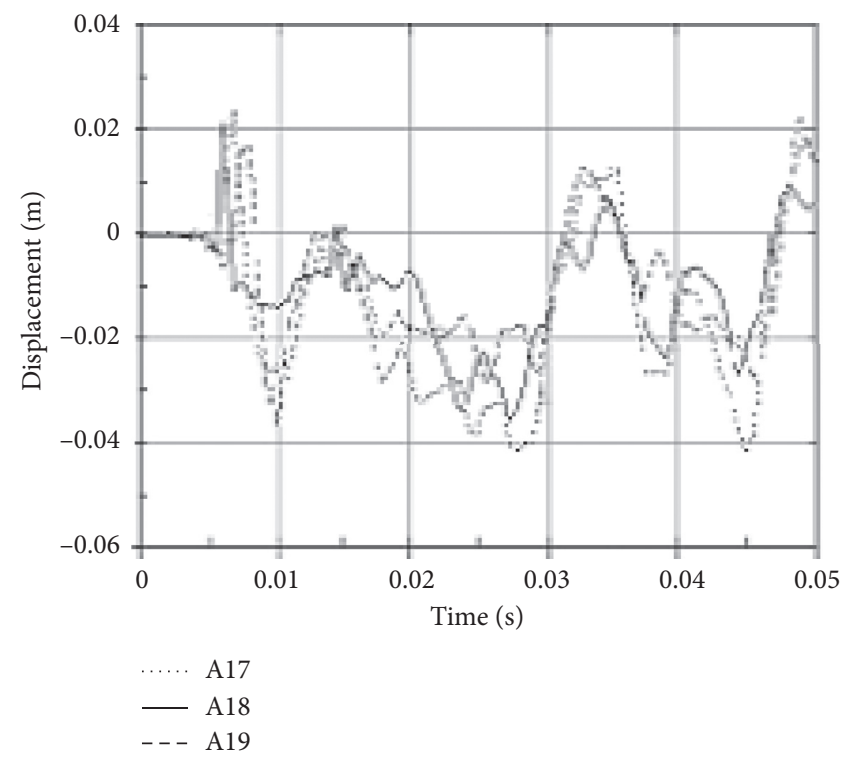

(d)

FIgURE 8: Changes of displacement in $x$-direction in sections. (a) Reference point of section one, (b) reference point of section two, (c) reference point of section three, and (d) reference point of section four.

3.2.1. Dynamic Response of Lining Structure under $10 \mathrm{~kg}$ TNT Explosion. From the numerical simulation results, it can be seen that the maximum vertical displacement points of each section occur at two reference points at the upper wall and the lower wall. Figure 6 is the $y$-direction displacement change curve at the upper wall and the lower wall of the four sections.

As can be seen from the $y$-direction displacement change curve shown in Figure 6, the lining structure has a displacement of $0.4 \mathrm{~cm}$ at section A1. The displacement change curve of the section closer to the explosion source decreases rapidly after experiencing a peak value, and the change trend is stable. As the distance from the centre of the explosion source increases, the $y$-direction displacement gradually decreases. Multiple displacement peaks appear at sections two, three, and four since the shock wave energy decays rapidly with the increase of distance. There is a large difference between the value and section one. The displacement of the reference point at a longer distance first appears as a small amplitude oscillation change under the reflection superposition effect of the shock wave. Therefore, under the explosion of $10 \mathrm{~kg}$ of explosives, the deformation peak value of the lining is $0.4 \mathrm{~cm}$, and the influence on the lining structure is within the elastic range. At the beginning of the explosion, the lining structure was subjected to tensile stress and had a maximum acceleration and velocity at point A1. Figure 7 is a velocity and acceleration variation curve in the $y$-direction of sections one and three. 


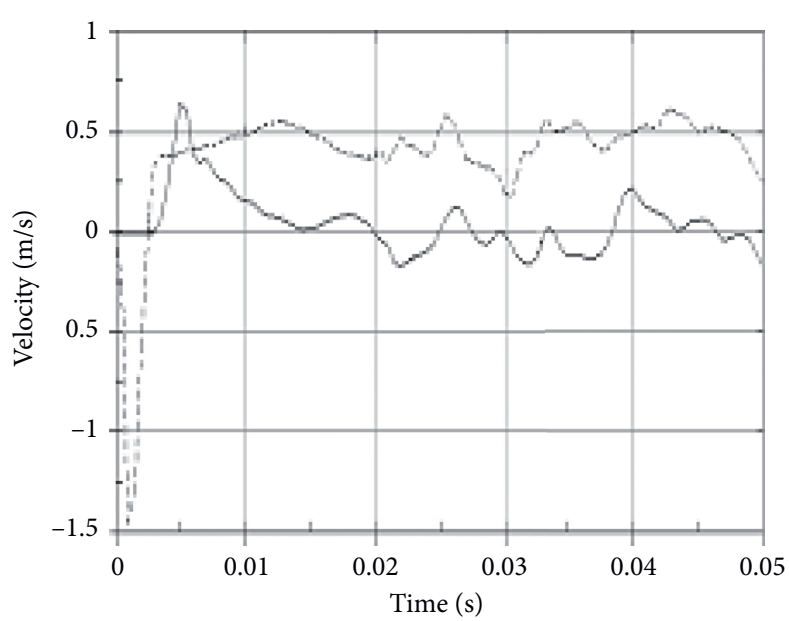

…. A1

- A5

(a)

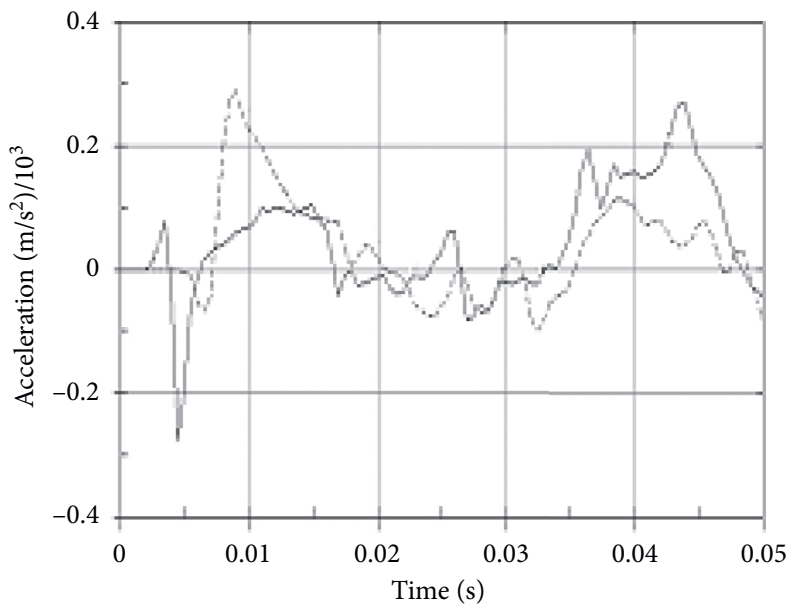

A11

- A15

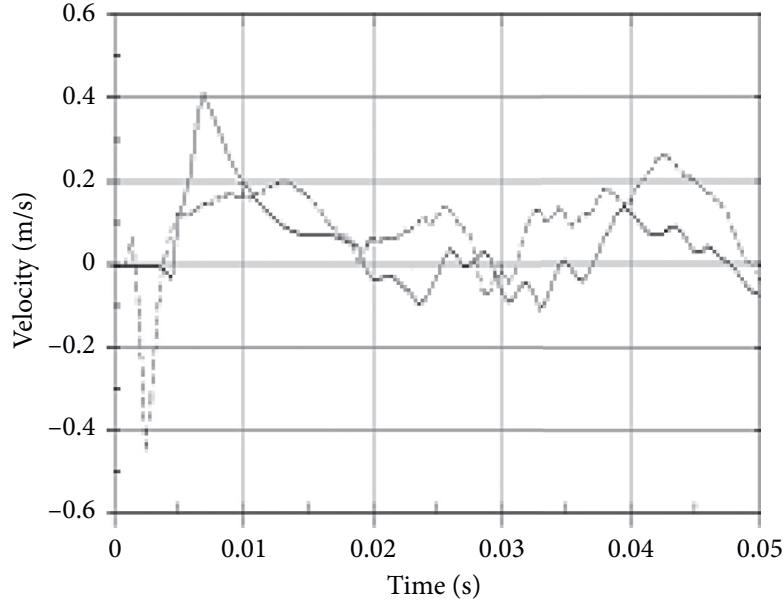

…. A1

- A5

(b)

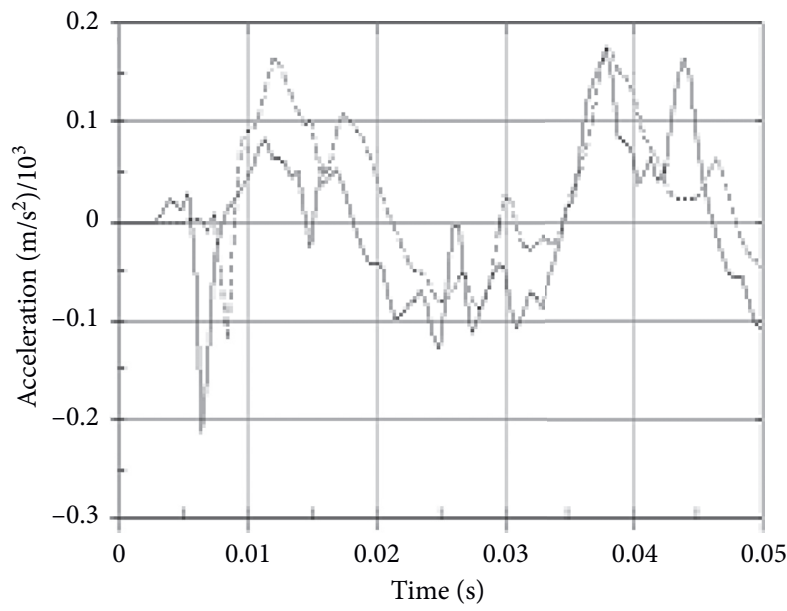

A11

- A15

(c)

(d)

FIGURE 9: Changes of displacement in $y$-direction in sections. (a) Velocity in $y$ direction of section one, (b) velocity in $y$ direction of section three, (c) acceleration of section one in $y$-direction, and (d) acceleration of section three in $y$-direction.

From the velocity and acceleration change curves shown in Figure 7, it can be seen that the displacement change of the reference point of section one rapidly decays after experiencing a peak value, while the displacement change of the reference point of other sections further away experiences multiple peaks, showing an overall weakening trend and a longer duration. This also verifies that the velocity and acceleration are affected by overpressure, and the magnitude of the impact is positively related to the distance from the explosive source. Under the action of explosion, the maximum horizontal displacement of five reference points in each section occurs at three points on the side wall. Figure 8 is the $x$-direction displacement change curve of four sections at three points.

From the $x$-direction displacement variation curve shown in Figure 8, it can be seen that the maximum displacement of $0.24 \mathrm{~cm}$ occurs at the reference point at the side wall A4 instead of the reference point at the front side wall A3. In addition, the impact of explosion shock wave on the displacement of the lining structure side wall is generally reflected in the second peak value, and the first peak value of displacement variation is caused by the vacuum zone formed by the sharp consumption of air during explosion. Under the superposition of multiple reflections of the shock wave, the displacement changes experienced multiple peaks and showed a weakening trend. By comparing the maximum velocity and acceleration in the $x$-direction with the maximum velocity and acceleration in the $y$-direction, we can see that there is a big gap between the two.

3.2.2. Dynamic Response of Lining Structure under $30 \mathrm{~kg}$ TNT Explosion. For the influence of explosion shock wave on lining structure under the action of higher explosive 


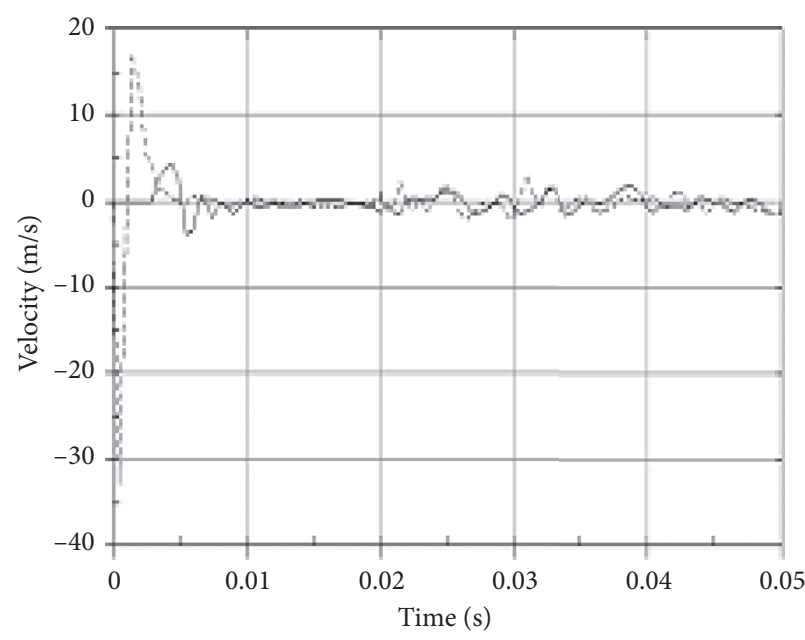

…. A1

- A5

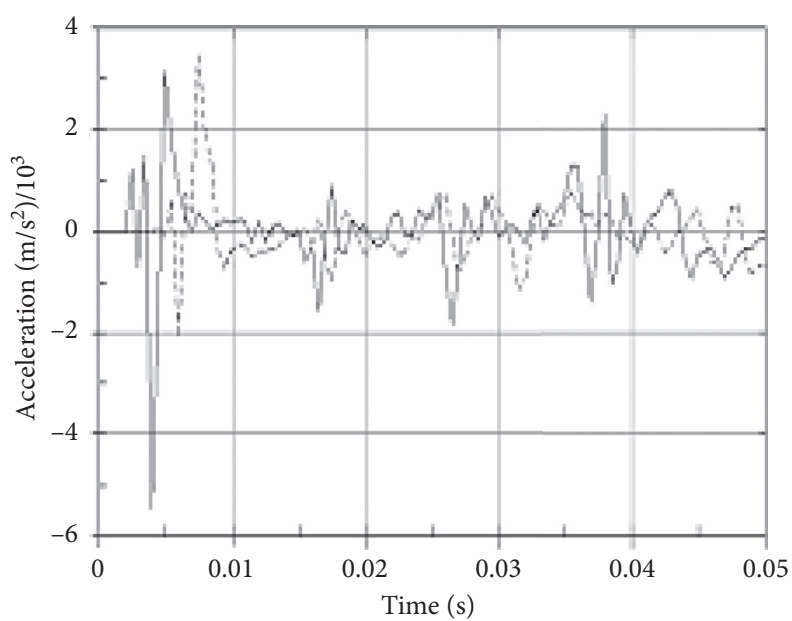

A11

- A15

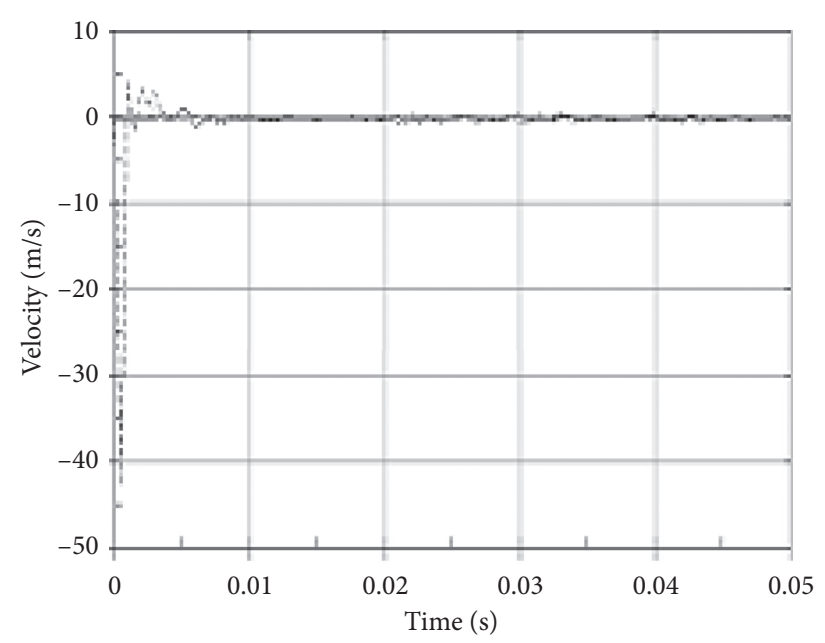

…. A 1

- A5

(b)

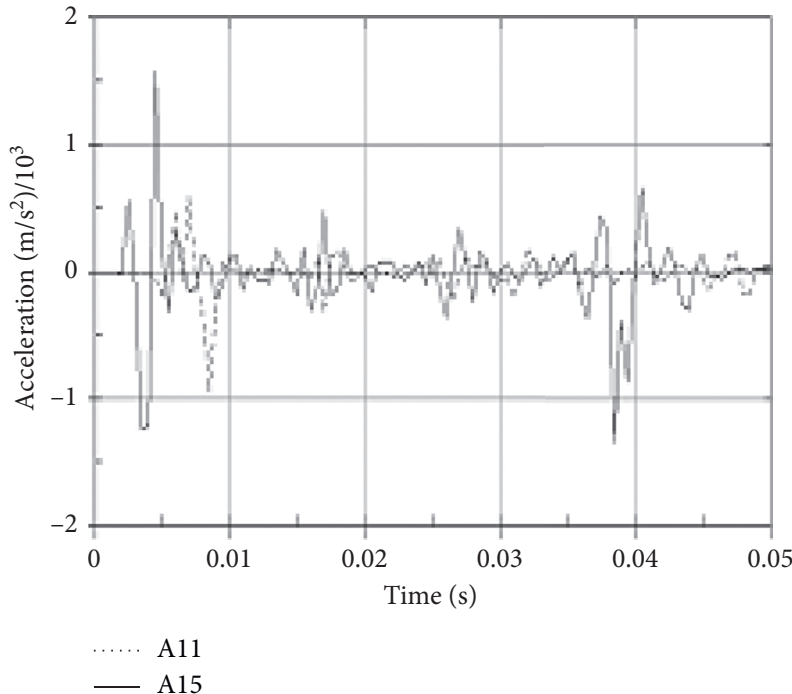

(d)

FIGURE 10: Velocity and acceleration curves in $y$-direction on each section. (a) Velocity in $y$-direction of section one, (b) velocity in $y$ direction of section three, (c) acceleration of section one in $y$-direction, and (d) acceleration of section three in $y$-direction.

equivalent, $30 \mathrm{~kg}$ TNT is selected for analysis. Each reference point is arranged in the same way as $10 \mathrm{~kg}$ TNT. Figure 9 is the $y$-direction displacement change curve at upper and lower walls of the four sections.

As can be seen from the $y$-direction displacement change in Figure 9, the maximum vertical displacement of each section occurs in two points on the upper and lower walls. The maximum displacement of A1 reference point of section one in $y$-direction is more than twice as much as that of section three under the action of $10 \mathrm{~kg}$ TNT. The displacement change curve shows a weakening trend as a whole. Therefore, the displacement of the lining structure close to the centre of the explosion source will increase at a high magnification when the amount of explosive increases exponentially. However, with the increase of distance, the displacement will increase at a low magnification and the influence will decrease gradually. There is an obvious plastic deformation at section one. It can be known that $30 \mathrm{~kg}$ TNT explosive exceeds the critical point of the plastic zone of the lining structure protected by composite steel plates.

According to the change curve in Figure 10, the change of velocity and acceleration in the $y$-direction is affected differently by the change of explosive charge. The multiple increase of explosive charge has the greatest impact on the area close to the explosive source. With the increase of distance, the impact gradually weakens. Within the range of $3 \mathrm{~m}$ from the explosive source, the velocity and acceleration will rapidly decrease after experiencing a main peak value and tend to be stable. Beyond the range of $3 \mathrm{~m}$ from the explosive source, the velocity and acceleration will slowly decrease after experiencing a main peak value. 


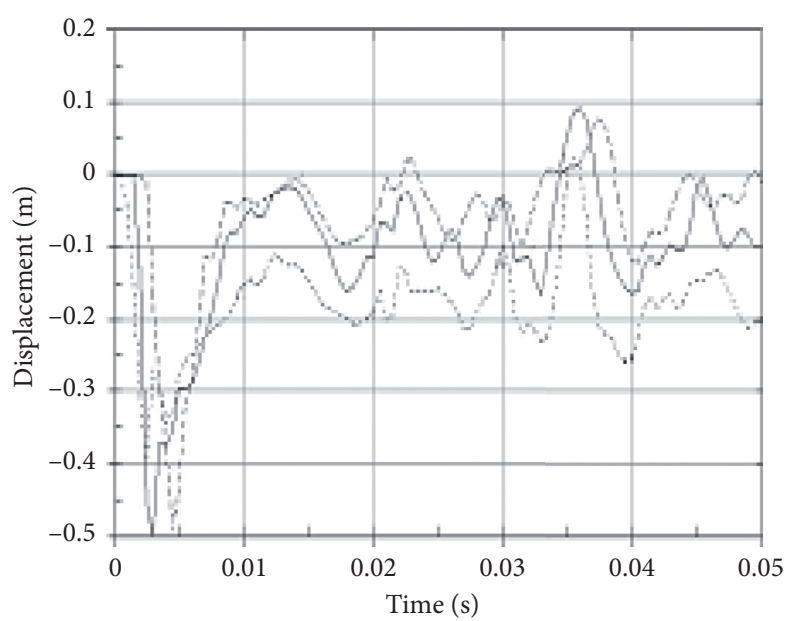

… A2

$-\mathrm{A} 3$

--- A4

(a)

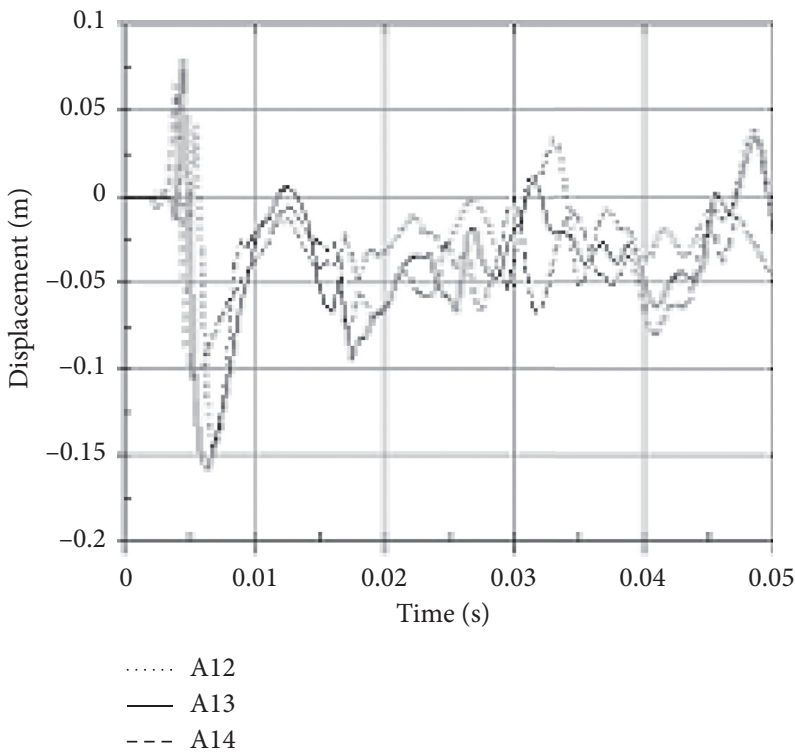

(c)

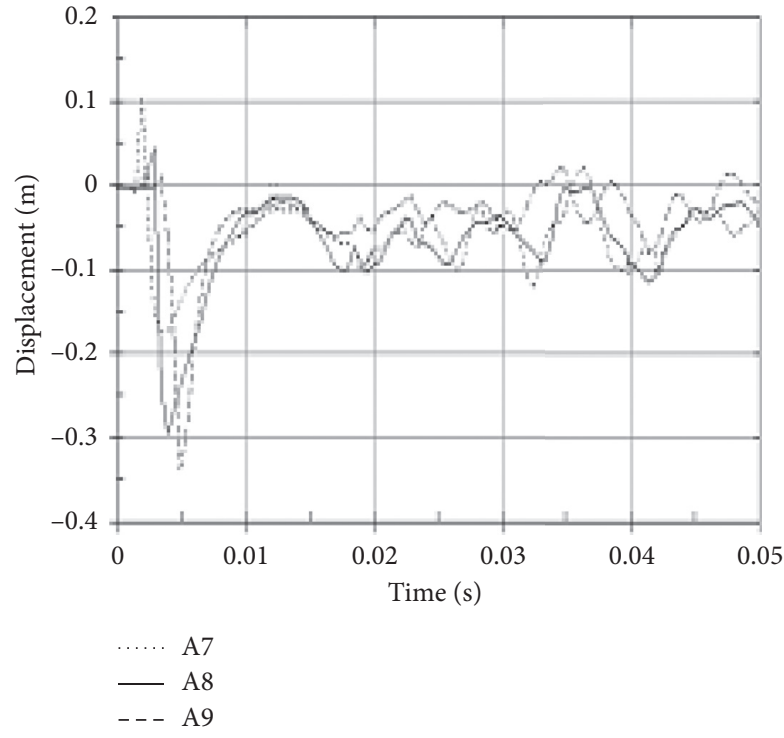

(b)

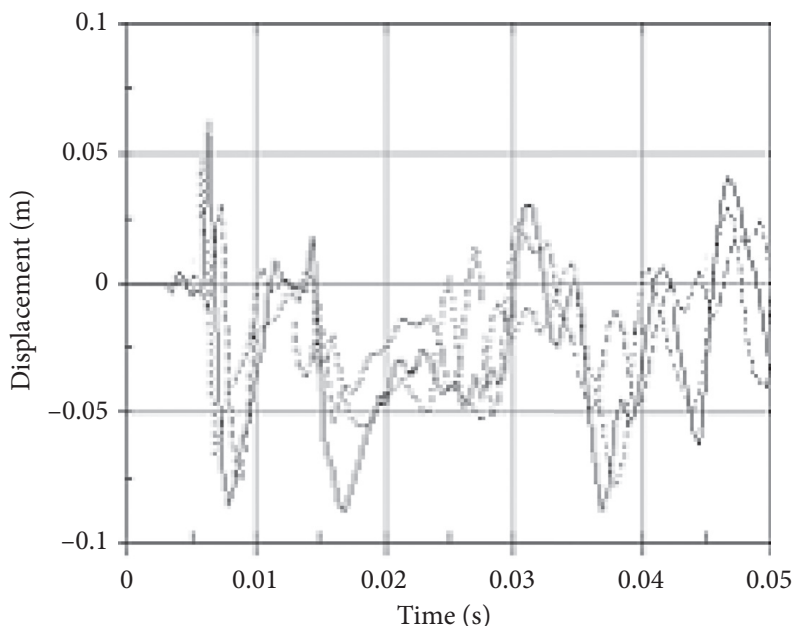

… A 18

- A17

- - A19

(d)

FIgURE 11: Changes of displacement in $x$-direction in sections. (a) Reference point of section one, (b) reference point of section two, (c) reference point of section three, and (d) reference point of section four.

Under the action of $30 \mathrm{~kg}$ TNT explosion, the maximum horizontal displacement of five reference points in each section occurs at three points on the side wall. Figure 11 is the $x$-direction displacement change curve of four sections at three points. By comparing the data of Figures 8 and 11, it can be concluded that the maximum displacement at four sections in the $x$-direction under the action of $30 \mathrm{~kg}$ TNT is about twice as large as that under the action of $10 \mathrm{~kg}$ TNT, slightly smaller than the maximum displacement increase in the $y$-direction at the same distance. At the same time, it can also be obtained through the displacement change curve of section one, and the damage effect of $30 \mathrm{~kg}$ TNT equivalent has exceeded the critical point, making the lining structure produce a plastic zone.
3.2.3. Variation Curve of Axial Overpressure under Explosion. For the variation of overpressure effect of explosion shock wave along the axial direction of lining structure, the 20 reference points $\mathrm{A} 1-\mathrm{A} 20$ are divided into five straight lines L1, L2, L3, L4, and L5, along the axial direction: the L1 straight line includes A1, A15, A11, and A16; L2 straight line includes A2, A7, A12, and A17; L3 straight line includes $\mathrm{A} 3, \mathrm{~A} 8, \mathrm{~A} 13$, and $\mathrm{A} 18$; L4 straight line includes A4, A9, A14, and A19; L5 straight line includes A5, A10, A15, and A20. Figures 12 and 13 are curves of axial overpressure change under explosion of $10 \mathrm{~kg}$ TNT and $30 \mathrm{~kg}$ TNT.

According to the attenuation law of overpressure on each straight line in Figure 12, the overpressure at the close 


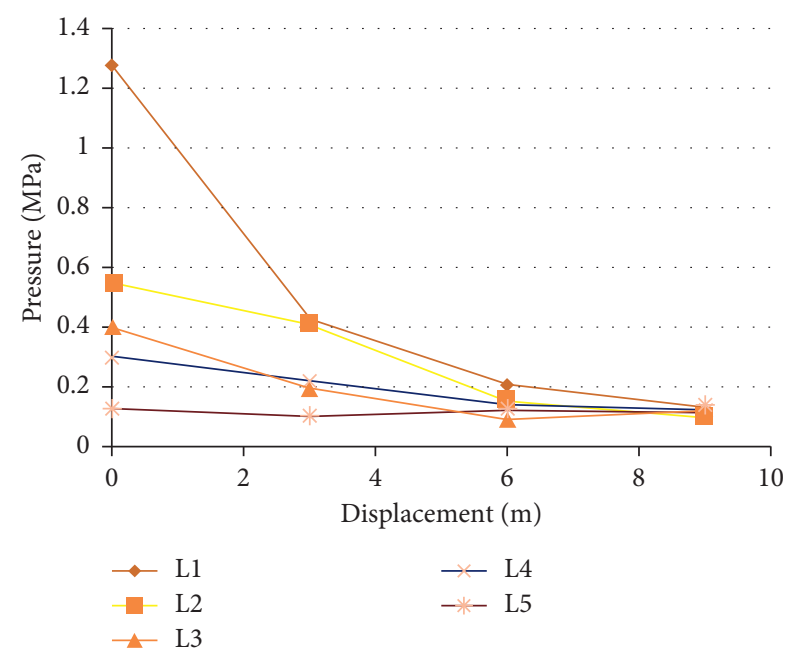

FIgURE 12: Overpressure attenuation laws in lines of $10 \mathrm{~kg}$ TNT.

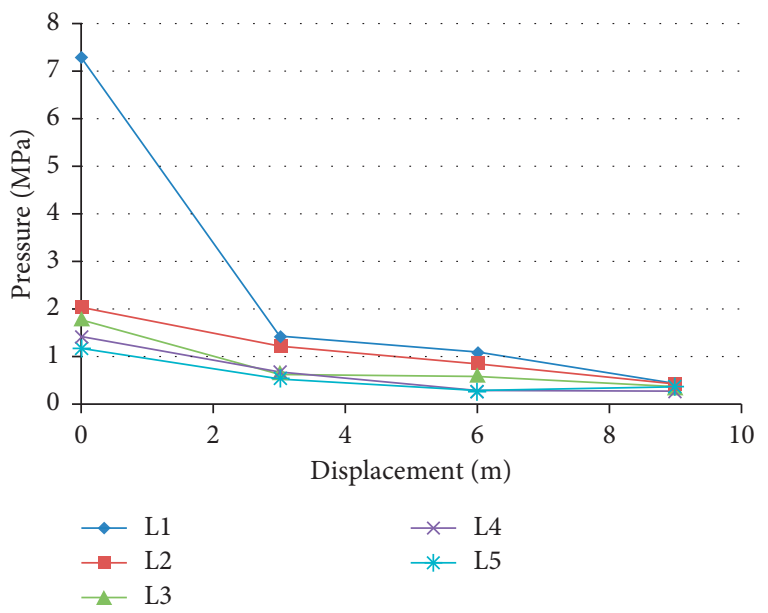

FIgURE 13: Overpressure attenuation laws in lines of $30 \mathrm{~kg}$ TNT.

distance from the lining structure is the strongest. The overpressure will decrease sharply in the range of $3 \mathrm{~m}$, and the overpressure will decrease slowly in the range of $3 \mathrm{~m} \sim 9 \mathrm{~m}$ as a whole. This is due to the rapid compression of air near the explosive at the initial stage of the explosion reaction, concentration of energy, and overpressure phenomenon. With the increase of distance, the energy will gradually diffuse [20]. The axial overpressure of the reference point within $6 \mathrm{~m}$ away from the centre of the explosion source will also increase slightly, which is due to the energy received by individual reference points increasing after the explosion shock wave is reflected and superimposed for many times.

By comparing the overpressure changes in Figures 12 and 13 , it can be seen that, at the beginning of the explosion, the overpressure peak value of $30 \mathrm{~kg}$ TNT increased by about six times compared with $10 \mathrm{~kg}$ TNT at the same reference point, which is much larger than the increase of explosive mass. Similar to the variation curve of overpressure of $10 \mathrm{~kg}$ TNT, the overpressure is strongest at the close distance from the centre of the explosion source. The overpressure has obvious attenuation at $3 \mathrm{~m}$ from the centre of the explosion source, and the overpressure keeps a slow attenuation trend in the range of $3 \mathrm{~m} \sim 9 \mathrm{~m}$. The overpressure of the reference point in the same straight line beyond $6 \mathrm{~m}$ will also be strengthened, which is also due to the superposition of multiple reflections of the explosion shock wave.

\section{Conclusions}

The instantaneous dynamic response of the lining structure installed with composite steel plate when explosion occurs is simulated by establishing a composite steel plate lining structure model. Different influencing factors are determined, and parameterized analysis is carried out by using the method of comparison of different explosive equivalent explosion effects. The following conclusions are obtained.

(1) The change of velocity, acceleration, and displacement of each reference point at the lining structure is related to the action of overpressure and distance. A main peak value will be formed within $3 \mathrm{~m}$ from the explosion source, and the peak value is obviously higher than other peaks. With the propagation of explosion shock wave, the function of lining structure will gradually decrease.

(2) The effect of multiple increase of explosive quantity on each point of lining structure is not the same. The acceleration near the distance is generally far greater than the multiple increase of explosive quantity, while the increase of velocity and displacement is basically the same as the explosive quantity. The effect of multiple increase of explosive quantity on acceleration, velocity, and displacement is reduced, and the change is relatively stable at a distance $(3 \mathrm{~m}$ away from the explosive source).

(3) By comparing the data changes of acceleration, velocity, and displacement in each direction of the same reference point, it can be seen that, under the action of explosion, when the distance is relatively close, the influence is greater, the axial stress has the least influence on the lining structure, and the influence of $y$-direction of the lining section on the lining structure is greater than the other two directions.

\section{Data Availability}

The raw/processed data used to support the findings of this study have not been made available because they form part of the ongoing research.

\section{Conflicts of Interest}

The authors declare that they have no conflicts of interest regarding the publication of this paper.

\section{Acknowledgments}

This work was supported by the Natural Science Foundation of China (41372288) and Shandong Natural Science Foundation (ZR2019MEE027). 


\section{References}

[1] Q. H. Meng, Dynamic Response and Explosion-Resist-Antprotection of Subway Tunnel under Terroristbom-Bing load, Shandong University of Science and Technology, Qingdao, China, 2010.

[2] D. S. Kong, M. Y. Deng, and Y. Z. Li, "Experimental study on mechanical deformation characteristics of inclined and straight alternating pile groups," Advances in Civil Engineering, vol. 2020, Article ID 8394182, 11 pages, 2020.

[3] D.-S. Kong, Q.-H. Meng, W.-W. Zhang, and Q.-H. Zhang, "Shock responses of a metro tunnel subjected to explosive loads," Journal of Vibration and Shock, vol. 31, no. 12, pp. 69-72, 2012.

[4] J. B. Liu and Q. S. H. Ni, "Study on explosion protectionin iron underground structure," Journal of Vibration and Shock, vol. 27, no. 8, pp. 16-19, 2008.

[5] A. Zyskowski, I. Sochet, G. Mavrot, P. Bailly, and J. Renard, "Study of the explosion process in a small scale experimentstructural loading," Journal of Loss Prevention in the Process Industries, vol. 17, no. 4, pp. 291-299, 2004.

[6] C. L. Yan and D. J. Ma, "High resolution numerical simulation of strong explosive waves in a vessel," Journal of China University of Science and Technology, vol. 25, no. 1, pp. 10-16, 1998.

[7] Y. Z. Cao, Z. S. Lu, and H. A. Guan, "Numerical simulation of explosion flow field in anti-explosion vessel," Journal of China University of Science and Technology, Chinese Journal of High Pressure Physics, vol. 15, no. 2, pp. 127-133, 2001.

[8] Y. Cui, Dynamic Response and Damage Assessment of Duplex Hollow CFST Column Subjected to Blast Loading, Changan University, Xi'an, China, 2013.

[9] D. S. Kong, M. X. Deng, and Z. M. Zhao, "Seismic interaction characteristics of an inclined straight alternating pile groupsoil in liquefied ground," Advances in Civil Engineering, vol. 2019, Article ID 3758286, 12 pages, 2019.

[10] K. Z. Yang and X. M. Yang, "The propagation law of the impulse shock wave in the tunnel," Explosion and Shock Waves, vol. 23, no. 1, pp. 37-40, 2003.

[11] A. L. Kuhl and H. Reichenbach, "Combustion effects in confined explosions," Proceedings of the Combustion Institute, vol. 32, no. 2, pp. 2291-2298, 2009.

[12] D. Kong, M. Deng, Y. Liu, and X. Tan, "Study of the force and deformation characteristics of subsea mudmat-pile hybrid foundations," Polish Maritime Research, vol. 25, no. s3, pp. 43-53, 2019.

[13] S. H. Qu, Structural Response and Damage and Ground Vibration of Subway Station under Internal Explosion, Tianjin University, Tianjin, China, 2008.

[14] X. L. Du, W. Z. H. Liao, M. Z. H. Tian et al., "Numerical simulation of flow around blast wave," Journal of Beijing University of Technology, vol. 34, no. 3, pp. 277-287, 2008.

[15] D. S. Kong, M. X. Deng, and Y. Xu, "Study on calculation of pile sliding interval of large-diameter steel pipe piles on offshore platforms," Mathematical Problems in Engineering, vol. 2019, Article ID 3549296, 8 pages, 2019.

[16] Y. F. Liu, R. H. Liu, S. Q. Shi et al., "Numerical stimulation on analysis of reducing blast by using foam aluminum," Chinese Journal of Underground Space and Engineering, vol. 27, no. 8, pp. 16-19, 2008.

[17] D. S. Kong, Y. F. Bai, Y. P. Chen, and M. X. Deng, "A study on the seismic response characteristics of an oblique pile groupsoil-structure with different pile caps," Shock and Vibration, vol. 2019, Article ID 8141045, 12 pages, 2019.
[18] D. S. Kong, M. X Deng, and Y. Z. Li, "Numerical simulation of seismic soil-pile interaction in liquefying ground," IEEE Access, vol. 8, no. 1, pp. 195-204, 2020.

[19] D. S. Kong, Y. Liu, M. X. Deng, and X. Y. Zhao, "Analysis of influencing factors of lateral soil resistance distribution characteristics around monopole foundation for offshore wind power," Applied Ocean Research, vol. 97, Article ID 102106, 2020.

[20] W. W. Zhang, Study of Impulse Response and Shield Technology of Subway Station under Terrorist Explosion load, Shandong University of Science and Technology, Qingdao, China, 2010. 